\title{
An Assessment of Cohesion and Coherence in Students' Descriptive and Narrative Essays: The Case of Sodo Preparatory School Grade Eleven Students'
}

\author{
Abebayehu Anjulo Alaro \\ Department of English Language and Literature, Arba Minch University
}

\begin{abstract}
This study is aimed to assess the students' use of cohesion and coherence in their descriptive and narrative essays. It was conducted at Sodo preparatory school on grade 11 students. The study employed the descriptive research design. In this study, 30 grade eleven students were selected as participants through simple random sampling technique. Document analysis was used to collect data from the sample students. The data collected through document analysis were analyzed qualitatively based on the analysis parameters of cohesive substitution, ellipsis, reference, conjunction and lexical cohesion to determine meaningfully (coherently) written students' essays. The findings revealed that students' used a variety of cohesive devices in each genre of writing except ellipsis and they employed all sub categories of cohesive signals in their (descriptive and narrative) essays. However, among the frequently used cohesive devices, the largest numbers of connectors were inappropriately instanced regarding the total use of devices. The students' inappropriate use of cohesive devices mainly appeared with conjunction, followed by reference, lexical cohesion, and substitution signals. As a result, the essays lacked consistent key expressions, clear purpose of the statement, and the logical shift from one sentence to the other. Based these findings, conclusions and recommendations were made.
\end{abstract}

Keywords: Cohesion, Coherence, Descriptive and Narrative Essays.

DOI: $10.7176 / \mathrm{JLLL} / 64-05$

Publication date: January $31^{\text {st }} 2020$

\section{Introduction}

Writing is one of the four language skills that people learn in English language like listening, speaking and reading. It is an important tool of communication. According to Graham et al (2012:1)"writing is a valuable tool for communication, learning and self-expression." In addition this Atkins, Nuru and Hailom (1996:114) state that "as a writer one has to consider who the reader is, what he knows, and how he will understand and react to what is written.' As students learn their preparatory education level, they have to consider the use of cohesion and coherence in writing to produce logically connected ideas or expressions in certain place and time to the reader. Richards and Renandya (2002) say that writing skills consists of many constituent parts; such as content, organization, unity, cohesion, coherence, fluency, accuracy or using appropriate rhetorical forms of discourse. So understanding the fundamental parts of writing skills provide the preparatory education level students to convey their ideas in coherent way to produce appropriate essays.

The practice of essay writing is one of the basic ways of developing writing skills, whether the form is descriptive, narrative, expository and argumentative and it also involves the rhetorical matters of taking account of cohesion and coherence. In a well-constructed essay, a group of sentences are connected and arranged in a logical order to provide an appropriate details or information in a single topic or theme. Lee (2002) defines coherence as the relationship of varies ideas in an essay that are linked together to create a meaningful text. In line with this, Tanawong(2014)points out cohesion is the use of cohesive ties to sequences and sentences together, facilitating text to be understood as connected ideas. In addition this Carter (1999) suggests that cohesion is linguistic relation which is developed between clauses and how the surface linguistic elements of the text are linked to each other in order to create unified essays. These show that a coherent essay can be achieved through cohesive ties. Thus, understanding the concept of cohesion and coherence play an integral role in essays writing and it also involves recognizing how the ideas in essays connected and how these connections are expressed in a logical manner. Therefore, if these two key terms (cohesion and coherence) are clear to students, they may write a meaningful intended text to pass clear information to a reader in certain contexts.

In general, an assessment of cohesion and coherence in students' essays is the act of collecting valuable information about the situation to identify their writing ability which is associated with essays writing. According to Harmer (2004:262) "the students writing skill is very important to identify students' practices of basic qualities of essays writing such as; coherence, cohesion and unity." Hence, students at preparatory education level are expected to write different types of essays in the knowledge of coherence and cohesion. 


\section{Statement of the problem}

The use of cohesion and coherence in writing skills play a significant role in students' effective communication and academic success. This is because they are crucial issues in writing and also support students' to construct logically connected sentences and paragraphs in essays to convey their ideas clearly to a reader

However, as it was the case in Woliata Zone: Sodo Preparatory School (grade 11 and 12 levels), the majority of students were less familiar with the use of cohesion and coherence in essays because they did not have clear understanding of using appropriate ties in order to produce a coherent essays. Since the case was serious, most students faced challenges to organize their ideas to write an appropriate essay. If students do not have sufficient understanding of the use of coherence and cohesion of writing, they may not produce logically connected text to the reader. In this regard, the researcher was interested to assess students' use of cohesion and coherence in their essays at English classroom in the target school.

Regarding the problem, some studies were conducted locally and internationally in the area of cohesion and coherence in writing. Locally, the study has been done by Mohammed (2015) focused on assessing students' paragraph writing skills to examine the common problems of students' paragraph writing. The finding of the study indicated that the students had a lot of problems in paragraph writing such as organization, grammar, capitalization, spelling, punctuation, and unity. Kebede (2013) indicated that assessment on cohesion and coherence of students' paragraph writing. The study focused on identifying the factors that impede the cohesion and coherence of students' paragraph writing. The result of the study shows that students could not use appropriate cohesive devices to organize ideas in paragraph writing. In addition, internationally Suningsih (2016) carried the study on the use of cohesive devices in students' writing. The purpose of the study was to analyze the correctness of cohesive devices by Indonesian English major students. The results of the study indicated that students could not produce various types of cohesive devices in their writing. Furthermore, Sanczyk (2010) focuses on investigating argumentative essay in the use of cohesive devices. In the study, the researcher aimed to assess the use of cohesive devices in argumentative essays written by polish undergraduate majoring students in English. The findings of the study proved that students used cohesive devices in their argumentative essay. The international researchers investigated only on cohesion but they did not focus on coherence in essays.

As it has been mentioned, the local and international studies which were conducted in the area of writing focused on paragraph, argumentative essay and academic writing. For instance, locally, the works of Mohammed (2015) and kebede (2013) concerned with the practice of assessing students' paragraph writing problems, though their focus was at different levels. That was, Mohammed made a study on assessing students' paragraph writing problems at Bedeno secondary school students. Again also Kebede (2013) focused on assessment of cohesion and coherence in students' paragraph writing at Bedeno preparatory school. likewise, internationally, Suningsih (2016) made an attempt in use of cohesive devices in students' academic writing: the case of Bardar Lampund University students'; whereas Sanczyk (2010) carried on investigating argumentative essays of English undergraduate studying in Poland as regard their use of cohesive devices.

As far as the researcher's knowledge is concerned, the local and international studies which were conducted in the area of writing focus little about assessing students' essay writing skills and the others are based on academic and argumentative essay in English classroom. In general, the previous studies were related to this study in that they were based on the issues of writing skills. In fact, kebede's work, i.e. assessment on cohesion and coherence of students' paragraph writing, seems to have some similarities with this study. However, his prime focus was the use of cohesion and coherence in a paragraph level that EFL learners face challenges in paragraph writing. He did not investigate coherence and cohesion in essay writing level. Besides, kebede investigated in Bedano preparatory school, while the present researcher investigated in Wolaita Sodo preparatory (grade11 and 12 levels) school. Thus, the present study focused on an assessment of cohesion and coherence in students' descriptive and narrative essays at Sodo preparatory school.

\section{Objectives of the study}

In this study, the researcher designed the following general and specific objectives.

\subsection{General objective}

The overall objective of this study was to assess grade eleven students' use of cohesion and coherence in descriptive and narrative essays at Sodo Preparatory School.

\subsection{Specific objectives:}

To identify the students' use of appropriate cohesive devices in descriptive and narrative essays , and

To assess the students' ability of composing coherent descriptive and narrative essays.

\section{Research Methodology}

This part presents the research design, participants of the study, sampling techniques and sample size, data 
gathering instrument, data collection procedures and methods of data analysis.

\subsection{Research Design}

The researcher used a descriptive design to conduct the study because it describes the natural phenomena and real data so as the researcher may get important information for the study. Jeane (1999) stated that the descriptive research design is used to obtain information concerning the current status of the phenomena and to describe what exists with respect to condition in a situation. By the same token, Cohen, Manion, and Morrison (2000) say that descriptive research is used to describe about problems that exist; process that are going on; effects that are being felt; or trends that are developing.

\subsection{Participants of the study}

The researcher conducted the study in governmental preparatory school named Sodo Preparatory School located in SNNP region, Wolaita Zone: Sodo town, particularly on grade eleven (11) students. The school was purposely chosen for the study because the researcher has been teaching English language for many years in the school. In this study, grade 11 students were participated to offer information about the general situation of cohesion and coherence in descriptive and narrative essays.

\subsection{Sample size and Sampling techniques}

Sodo Preparatory School is selected to be the setting of the study. The reason was that the researcher had experience about the presence of the problem. Regarding the case, the researcher used grade 11 students to conduct the study. In grade 11, there were 6 sections. Each section comprises 50 students. The total number of students in these sections is 300 . From these, the researcher selected $30(10 \%)$ students (that was, 5 students from each section) as a sample population for the study through simple random sampling technique. Dornyei (2007 says that simple random sampling gives an equal chance for each member of the population under the study.

\subsection{Data gathering instrument}

The instrument that the researcher employed to collect data for the study was document analysis. The main purpose that the researcher used document analysis was to originate valid information about cohesion and coherence in students' essays. Brown (2009) claimed that document analysis is an efficient and effective way of gathering data because documents are manageable and practical resources. Moreover, Stemler and Bebell (1998) confirmed that document analysis is a technique which can generate both valid and reliable data from documents; and it is a technique for understanding and analyzing the mission statements of people's selected documents. As a result, it was employed to get real data for the use of cohesion and coherence by grade 11 students' in their essays. Thus, the researcher gave topics for participant students' to compose the descriptive and narrative essays to get pertinent information for the study.

\subsection{Data collection procedures}

The data of this study was conducted on the following procedures. That was, the researcher gave topics on descriptive and narrative essays one after the other in two week's interval to the participant students in order to get important information from them. These tasks were given in the following procedures: first, descriptive essay writing topic was given to the sample students. Then, the researcher administered the narrative essay writing topic to the sample students.

\subsection{Methods of data analysis}

To analyze the collected data, the researcher used the qualitative content analysis method. Dornyei (2007) acknowledged that qualitative content analysis is a procedure for the categorization of verbal or written data, for purpose of classification and tabulation. Hence, the researcher used the following methods to analyze students' use of cohesive devices in their descriptive and narrative essays. This is to mean that the researcher first coded for each sample students' as S1, S2, and S3 ---S30 to collect data about cohesive devices in their essays. Next, he concentrated to count the frequencies of students' use of cohesive devices on average use of words and sentences level. Then, the researcher carefully checked appropriately and inappropriately used cohesive devices to determine meaningfully written students descriptive and narrative essays.

\section{Results and Discussions}

This section includes the results and discussions of data obtained from students' document analysis. The data were analyzed thematically based on the criteria of analysis. The analyses of the data (descriptive and narrative essays) were carried out in accordance with the research objectives, i.e. the students' use of appropriate cohesive devices such as substitution, ellipsis, reference, conjunction and lexical cohesion, and the students' ability of 
composing coherent essays. Furthermore, the students' each genre of writing could be analyzed based on average use of cohesive devices were used in each word and sentence level. This enabled the researcher to identify the actual frequency of cohesive devices in students' descriptive and narrative essays. Then, the researcher concentrated on the students' appropriate and inappropriate use of cohesive devices to determine logically written students' essays.

\subsection{The appearance of cohesive devices in students' descriptive essay}

The purpose of this section expresses the frequency and percentage occurrences of cohesive devices used in students' descriptive essay to be analyzed in appropriate context.

Table 5.1.The categories of cohesive devices and frequency in students' descriptive essay

\begin{tabular}{|c|c|c|c|c|c|c|c|c|c|c|c|c|c|}
\hline \multirow{2}{*}{\multicolumn{2}{|c|}{\begin{tabular}{|l|l|} 
& $\begin{array}{l}\text { No of } \\
\text { students }\end{array}$ \\
\end{tabular}}} & \multirow{2}{*}{$\begin{array}{l}\text { No of } \\
\text { words } \\
\text { on } \\
\text { average }\end{array}$} & \multirow{2}{*}{$\begin{array}{l}\text { No of } \\
\text { sentences } \\
\text { on average }\end{array}$} & \multirow{2}{*}{$\begin{array}{l}\text { Criteria on } \\
\text { cohesion }\end{array}$} & \multirow{2}{*}{$\begin{array}{l}\text { № of cohesive } \\
\text { devices } \\
\text { Frequency On } \\
\text { average }\end{array}$} & \multirow{2}{*}{$\%$} & \multirow{2}{*}{$\begin{array}{l}\text { Sub titles of } \\
\text { cohesive devices }\end{array}$} & \multirow[t]{2}{*}{ Frequency } & \multirow{2}{*}{$\%$} & \multicolumn{2}{|l|}{ Appropriate } & \multicolumn{2}{|c|}{ Inappropriate } \\
\hline & & & & & & & & & & Frequency & $\%$ & Frequency & $\%$ \\
\hline & \multirow{15}{*}{30} & \multirow{15}{*}{292} & \multirow{15}{*}{17} & \multirow[t]{3}{*}{ Substitution } & \multirow[t]{3}{*}{2.56} & \multirow[t]{3}{*}{3.3} & Nominal & 1.54 & 1.99 & 0 & 0 & 1.54 & 1.99 \\
\hline & & & & & & & Verbal & 0.61 & 0.79 & 0 & 0 & 0.61 & 0.79 \\
\hline & & & & & & & Clausal & 0.41 & 0.53 & 0 & 0 & 0.41 & 0.53 \\
\hline & & & & \multirow[t]{3}{*}{ Ellipsis } & \multirow[t]{3}{*}{0} & \multirow[t]{3}{*}{0} & Nominal & 0 & 0 & 0 & 0 & 0 & 0 \\
\hline & & & & & & & Verbal & 0 & 0 & 0 & 0 & 0 & 0 \\
\hline & & & & & & & Clausal & 0 & 0 & 0 & 0 & 0 & 0 \\
\hline & & & & \multirow{3}{*}{ Reference } & \multirow[t]{3}{*}{27.92} & \multirow[t]{3}{*}{36.2} & Personal & 13.96 & 18.11 & 4.97 & 6.45 & 8.99 & 11.66 \\
\hline & & & & & & & Demonstrative & 9.97 & 12.93 & 3.61 & 4.68 & 6.36 & 8.25 \\
\hline & & & & & & & Comparative & 3.99 & 5.17 & 0 & 0 & 3.99 & 5.17 \\
\hline & & & & \multirow[t]{4}{*}{ Conjunction } & \multirow[t]{4}{*}{34.3} & \multirow[t]{4}{*}{44.5} & Additive & 14.21 & 18.44 & 5.56 & 7.22 & 8.65 & 11.22 \\
\hline & & & & & & & Adversative & 8.24 & 10.7 & 3.12 & 4 & 5.12 & 6.7 \\
\hline & & & & & & & Causal & 6.21 & 8.05 & 2.56 & 3.32 & 3.65 & 4.73 \\
\hline & & & & & & & Temporal & 5.64 & 7.31 & 2.23 & 2.9 & 3.41 & 4.4 \\
\hline & & & & \multirow{2}{*}{$\begin{array}{l}\text { Lexical } \\
\text { cohesion }\end{array}$} & \multirow[t]{2}{*}{12.3} & \multirow[t]{2}{*}{16} & Reiteration & 7.4 & 9.61 & 2.65 & 3.45 & 4.75 & 6.16 \\
\hline & & & & & & & Collocation & 4.9 & 6.37 & 1.6 & 2.08 & 3.3 & 4.29 \\
\hline Total & 30 & 292 & 17 & & 77.08 & 100 & & 77.08 & 100 & 22.3 & 34.1 & 54.78 & 65.9 \\
\hline
\end{tabular}

Cohesion refers to the range of grammatical and lexical possibilities that exist for linking ideas in essays explicitly through cohesive elements. As analysis disclosed in table 4.1, students produced their descriptive essay on average use of 292 words and 17 sentences. This essay also concerned the use of cohesive devices such as substitution, references, conjunction and lexical cohesion. In fact, the elliptical ties were not considered in this essay. Regarding the average instances of cohesive signals, the conjunctive elements had been taken the dominant position and which appeared with 34.3(44.5\%). A long with this, the additive one contained $14.21(18.44 \%)$, followed by $8.24(10.7 \%)$ of adversative, then $6.21(8.05 \%)$ of causal and $5.64(7.31 \%)$ of temporal devices. Additionally, the reference devices also used to make meaning relation between parts the essay supplying one element with the other. The three sub categories of references ties: namely; personal, demonstrative and comparative were occurred in students' descriptive essay. As far as it was concerned there was $27.92(36.2 \%)$ of reference devices instanced in parts of the text. Besides, the $13.96(18.11 \%)$ of personal, $9.97(12.96 \%)$ of demonstrative and $3.99(5.17 \%)$ of comparative references signals appeared. Moreover, the lexical cohesion was also stated in the text in order to bring the semantic relation between words, phrases, sentences and paragraphs to create a logical essay. The lexical cohesion could be analyzed into two categories such as, reiteration and collocation. It was clearly presented in the above table, the $12.3(16 \%)$ of lexical cohesive ties were used in the students' descriptive essay. Out of this, the $7.4(9.6 \%)$ of reiteration and $4.9(6.36 \%)$ of collocation devices had averagely been frequented in the text. Furthermore, the least percentage of substitution devices or $2.56(3.32 \%)$ were occurred in this genre of writing. A long with this, the nominal one appeared with $1.54(1.99 \%)$, then $0.61(0.79 \%)$ of verbal and $0.41(0.53 \%)$ of clausal substitution ties.

Regarding inappropriate use of conjunctive devices, the result revealed that students' were unconscious of having different kinds of conjunctive connecters in order to keep the logical flow of the essay. It was clearly stated in the text, from the inappropriateness, the additive one predominated, followed by adversative, causal and temporal devices. This was because students' gave little attention for conjunctive categories to identify their clearer purposes when constructing their descriptive essay. Similarly, Suningsih( 2016) said that the wrong use of conjunctive elements between sentences or parts of the text cannot create meaningful expressions for a reader.

Moreover, it is clearly stated in the result section, the wrong use of reference devices took the second position in students' descriptive essay. Among these, personal reference devices were frequented higher in number than the others. In fact, the essay totally lacked the proper use of clausal references. Regarding to this, Halliday (1994) supposed that the referential ties are parts of cohesive devices which make the semantic relation in the text. In relation to this the students' descriptive essay concerned the average use of both the reiteration and collocation sub categories of lexical cohesive devices. Besides these, the largest parts of connectors were wrongly used. Furthermore, this essay wrongly concerned a number of Substitution signals. In line with this, Osisanwo (2005) implied that the misuses of substitution devices unconstructively affect the clear message of the text. Therefore, this showed that the students had little awareness in appropriate use of cohesive devices in order to compose meaningful essay to a reader. 


\subsection{The instances of cohesive devices in students' narrative essay}

The students' use of cohesive devices in narrative essay could be analyzed accordingly.

Table 5.2. The students' use of cohesive devices and percentages

\begin{tabular}{|c|c|c|c|c|c|c|c|c|c|c|c|c|c|}
\hline & № of & № of & № of & Criteria on & & & Sub titles of & Frequency & & Appropriate & & Inappropri & \\
\hline & & & & & On average & & & & & Frequency & $\%$ & Frequency & $\%$ \\
\hline & & & & Substitution & 0 & 0 & Nominal & 0 & 0 & 0 & 0 & 0 & 0 \\
\hline & & & & & & & Verbal & 0 & 0 & 0 & 0 & 0 & 0 \\
\hline & & & & & & & Clausal & 0 & 0 & 0 & 0 & 0 & 0 \\
\hline & & & & Ellipsis & 0 & 0 & Nominal & 0 & 0 & 0 & 0 & 0 & 0 \\
\hline & & & & & & & Verbal & 0 & 0 & 0 & 0 & 0 & 0 \\
\hline & & & & & & & Clausal & 0 & 0 & 0 & 0 & 0 & 0 \\
\hline & 30 & 285 & 18 & Reference & & & Personal & 10.16 & 13.77 & 3.79 & 5.13 & 6.37 & 7.4 \\
\hline & & & & & 23.96 & 32.46 & Demonstrative & 7.98 & 10.81 & 2.16 & 2.92 & 5.82 & 7.89 \\
\hline & & & & & & & Comparative & 5.82 & 7.88 & 1.93 & 2.61 & 3.89 & 5.27 \\
\hline & & & & Conjunction & 36.76 & & Additive & 12.96 & 17.56 & 5.11 & 6.92 & 7.85 & 10.64 \\
\hline & & & & & & 49.81 & Adversative & 8.01 & 10.86 & 3.75 & 5.08 & 4.26 & 5.78 \\
\hline & & & & & & & Causal & 8.96 & 12.14 & 3.22 & 4.36 & 5.74 & 7.78 \\
\hline & & & & & & & Temporal & 6.83 & 9.25 & 3.11 & 4.21 & 3.72 & 5.04 \\
\hline & & & & Lexical & 13.08 & 17.73 & Reiteration & 7.65 & 10.37 & 3.16 & 4.28 & 4.49 & 6.09 \\
\hline & & & & cohesion & & & Collocation & 5.43 & 7.35 & 2.13 & 2.89 & 3.3 & 4.46 \\
\hline Total & 30 & 285 & 18 & & 73.8 & 100 & & 73.8 & 100 & 28.36 & 38.4 & 45.44 & 61.6 \\
\hline
\end{tabular}

Regarding in table 4.2, the result indicated that the students' composed their narrative essay on average use of 285 words and 18 sentences. Additionally, this type of essay was constructed through the use of cohesive devices such as reference, conjunction and lexical cohesion. In fact, it did not hold both the substitution and ellipsis sub categories. This was to mean that there were $0(0 \%)$ of both substitution and ellipsis elements utilized in this text. On the other hand, the other cohesive devices were clearly presented in different parts of the text. Among the frequently used devices, the conjunctive one had been taken to the dominant position and it also appeared on average the $36.76(49.81 \%)$. From these, the $12.96(17.56 \%)$ of additive, followed by $8.96(12.14 \%)$ of causal, $8.01(10.86 \%)$ of adversative and $6.83(9.25 \%)$ of temporal conjunctive elements were used by the students'. Additionally, the reference devices were instanced with 23.96(32.46\%). Among these, the personal one appeared with $10.16(13.77 \%)$, then $7.98(10.81 \%)$ of demonstrative and $5.82(7.88 \%)$ of comparative reference devices. Moreover, this essay also contained on average 13.08(17.73\%) of lexical cohesive devices. Out of these, $7.65(10.37 \%)$ of reiteration and $5.43(7.35 \%)$ of collocation devices appeared in different parts of the text respectively.

In terms of inappropriate use of cohesive devices, the largest part 45.44(61.6\%) of narrative essay concerned with the wrong use of signals. Along with these, 7.85(10.64\%) of additive, followed by 5.74(7.91\%) of causal, $4.26(5.75 \%)$ of adversative and $3.72(5.04 \%)$ of temporal showed the inappropriate occurrences of cohesive signals. Moreover, as it was indicated from the table, the essay clearly revealed that the inappropriate use of reference devices distribution with $6.37(7.4 \%)$ of personal, 5.82(7.89\%) of demonstrative and 3.89(5.27\%) of comparative signals. Furthermore, in lexical cohesion, the $4.49(6.09 \%)$ of reiteration and $3.3(4.46 \%)$ of collocation devices were also happened the same manner in students' narrative essay. The students' tended to follow certain techniques to organize their ideas in the text, but most sentences were isolated without any relation to one another, so the essay contained the random collection of sentences in each paragraph. The random collection of sentences made an essay incoherent. Therefore, this situation influenced the general quality of an essay and it also leaded difficulty to compose a coherent essay.

\section{Conclusions and Recommendations}

\subsection{Conclusions}

From this study the following conclusions were drawn:

The results and discussions revealed that students utilized in their descriptive and narrative essays all sub categories of cohesion signals except ellipsis; namely, substitution, reference, conjunction and lexical cohesion. From these, the conjunctive connectors were commonly instanced with a large number of ties and took the primary place compared with the other cohesive devices. In fact, the least percentages of substitution sub categories of cohesive signals appeared in students' descriptive and expository essay. However, the frequently occurred cohesive signals did not show their appropriateness. In spite of the fact that students' tended to utilize a lot of cohesive devices, most of their essays were illogically composed and gave senseless information for the reader. This indicated that students' essay contained considerable problems of cohesive signals. In case of this, most connectors were missed and overused, but few of them were completely neglected from the essays. This is to mean that the students' faced difficulties to employ the appropriate use of connectors in order to construct coherent essays. As a result, the essays left clear purpose of statement, concerned the illogical shift from one sentence from the other, tended to contain chunks of information which were not linked together as one organized whole, lacked consistent key expressions and strong conclusion part. 


\subsection{Recommendations}

Based on the conclusions drawn above, the researcher forwards the following recommendations as possible ways to address problems stated above:

1. Students' should focus on how to arrange ideas in sentence and paragraph levels using cohesive devices appropriately in order to construct logically connected essays. This is because logically connected texts are easier and give clearer message for the reader.

2. In the present study, since the students completely ignored the ellipsis sub categories, and appeared to use substitution devices in a poor manner (which can negatively affect the information in a text), so, they should give more attention to using all cohesive devices when constructing essays. Therefore, students should practice how to use each connecter appropriately to produce their ideas in a logical manner.

3. Students' should practice how to write the important parts of essays regarding introduction, supportive details, and conclusion paragraphs to keep the logical flow of ideas from one paragraph to the next.

4. The grade level English teachers should also provide as many opportunities as possible to their students' in order to practice composing essays using appropriate cohesion and coherence devices.

\section{References}

Atkins, J. Hailom,B and Nuru,M.(1996). Skills Development Methodology Part 2. Department of Forien Language and LIterature. Addis Ababa: Addis Ababa University.

Brown, G. (2009). Document analysis as a qualitative research method. Qualitative research journal,9(2), 27-40.

Carter, R. (1999). The Cambridge Guide to Teaching English to speakers of other Languages. Cambridge: Cambridge University Press.

Cohen,L. Manion,L and Morrison,K.(2000). Reaserch Methods in Education. London and Newyork: Rutledge Flamer.

Dornyei, Z. (2007). Research Methods in Applied Linguistcs: Qualitative,Quantitative and Mixed Methodologies . Oxford: Oxford University Press.

Graham, S. et al. (2012). Teaching Elementary School Students to be effective writers: A practice guide,Dc.National Center of Education and Regional assistance,Institute of Educational Sciences,US. Department of Education. Unpublished.

Halliday, M. (1994). An Introduction to Functional Grammar. London: Edward Arnold.

Harmmer, J. (2004). How to teach writing. Longman.

Jeane,W.(1999). Resaerch Design for Social work and the Human services. Chapter 5, Flexible methods : Descriptive Reaserch. $2^{\text {nd }}$ ed. New York: Colubia University press.

Kebede, A. (2013). Assessment on cohesion and coherence in students paragraph writing:The case of Bedeno Preparatory school,grade 12 English classes focus. HaramayUniversity.( unpublished).

Lee, I. (2002). "Helping students Develop coherence in writing." English Teaching Forum.

Mohammed, H.(2015). Assessing students' paragraph writing problems:The case of Bedano secondary school, grade 10 English class focus. Haramaya University.( unpublished)

Osisanwo, W. (2005). Introduction to Discourse Analysis and Pregmatics. Logis: Femulus Fetop Publishers.

Richards, J and Renandya, W.A. (2002). Methodology in Language Teaching: An anthology of current practice. Cambridge: Cambridge University Press.

Sanczyk, A. (2010). Investgating argumentative essays of English undergradute studying in Poland as regard their use of cohesive devices. Olson University.(Unpublished).

Stember, S. and Bebell, D. (1998). An Emprical Approach to understanding and analysing the mission statements of selected educational institutions. Ports mouth,New Hempshire,Available: DOC.NO.ED442202.

Suningsih, S. (2016). The use of cohesive devices in students writing. Barder Lampung: Lampung University.(Unpublished).

Tanawong, P.(2014). The relationship between cohesion and coherence in writing: The case of Thai EFL students. Srinakharinwirot: Srinakharinwirot University. (Unpublished). 